\title{
SOCIO-TECHNICAL STRUCTURE: An Experiment in Integrative Theory Building
}

\author{
Jeremy Rose \\ University of Aalborg
}

Rikard Lindgren

Viktoria Institute

Ola Henfridsson

Viktoria Institute

\begin{abstract}
When it comes to investigating the relationship between the social and the technical, the Information Systems (IS) discipline has been a net importer of theories. These theories often carry differing interpretations of central concepts, which then become both contusing and difficult to integrate. In response to calls for IS to become a reference discipline in its own right (in other words, a theory exporter), this paper offers an example of integrative theory development. Instead of adapting a theory from another discipline or building a theory from empirical data, we examine the structure concept in some of its various theoretical adaptations in IS and try to integrate them to produce theory focusing on IS concerns while resolving some of the major areas of contention. Both social and technological versions of structure are investigated through three theoretical IS perspectives drawn from different reference disciplines. The first perspective relates to social theories (principally structuration theory), the second to linguistic theories (principally the structural linguistics of Chomsky), and the last to science studies (principally actor-network theory). The objective is to study areas of agreement and contention around the structure concept. Areas of agreement can be incorporated into integrative theory development, whereas areas of contention must be resolved (a far more difficult task). The resulting theoretical model is illustrated with a case study involving competence management systems design and use at Volvo Information Technology in Göteborg, Sweden.
\end{abstract}

Keywords: Integrative theory development, socio-technical structure, theoretical IS perspectives 


\section{INTRODUCTION}

Primarily drawing its theory from reference disciplines, the Information Systems (IS) discipline can be described as an applied research field. This is often associated with discipline immaturity and sometimes prompts calls for IS to become a reference discipline in its own right (Baskerville and Myers 2002), usually followed by articles claiming that it now is (Nambisan 2003). Since the definition of applied is here theory importing, IS logically needs to become a theory exporter. This implies that there would be a body of reasonable integrated and consistent theory that related disciplines would find attractive, work with, and publish in their own journals. In this ambition, adaptive theory making (theory making which adapts a theory from another discipline) has two major drawbacks. The first is that it is not easy to re-export. The best that normally happens is that it provides a minor contribution to the original reference discipline. The second disadvantage is that it imports conceptual schemas carrying their own meanings, which conflict with the meanings of imports from other reference disciplines. For example, network in IS means rather different things depending on whether the reference discipline is communications, economics, mathematics, marketing, psychology, or science studies. The result is that IS theoreticians have rather few generally shared concepts to work with in the process of developing consistent theory.

In this paper, we develop an example of integrative theory development. Here we compare contributions in the IS literature from which to exploit different reference disciplines and try to discover what they have in common that is central to the IS tradition. In defining the IS tradition, we follow Lee (2001): it "examines more than just the technological system, or just the social system, or even the two side by side; in addition, it investigates the phenomena that emerge when the two interact." Thus, sociotechnical phenomena emerging in the context of designing, implementing, and using information systems are the platform for theory advances.

Starting with three examples of adaptive theory making (structurational, linguistic, and infrastructural accounts), we develop a theoretical model for capturing what is essential to IS, rather than what was essential to the contributing disciplines (Lee 2001). We do not start with an existing theory because this would normally be dependant on a reference discipline. Instead, we start with an empirical situation (the design and use of competence management systems at Volvo Information Technology, hereafter Volvo IT, in Göteborg, Sweden), and a much used (and abused) concept: structure. Structure is a term that is used in many different ways in the IS literature, for example, to mean a formal organizational power distribution, or the relation of the different parts of a computer program. However, we here examine structure primarily from the standpoint of a particular European tradition of thinking that has been influential in IS, where structure refers to the common enduring pattern both in social interaction, and in the linguistic and semiotic discourse in which those interactions primarily take place. In IS (unlike the original disciplines), discussions of structure should be related to computer systems, which are simultaneously systems of ideas expressed in the logic of software, and material (physical) systems. The objective of this paper is to present an integrative model of structure useful for both academics and practitioners in improving IS practice. The model is illustrated with a case study of competence system design and use at Volvo IT. 


\section{STRUCTURE AND TECHNOLOGY}

According to the Oxford English Dictionary, structure is "1, the way something is constructed or organized. 2, a supporting framework or the essential parts of a thing. 3 , a constructed thing; a complex whole; a building." In this section, we examine some of the prevalent theoretical uses of the term in the IS literature as it relates to technology and computer systems.

\subsection{The Dimensions of Structure}

Some features of the discussion are common across different theorizations of structure, such as the ordering of components, persistence (endurance or stability over time and space), influences on related events or understandings, where structure is understood to be situated. These common features are characterized as the dimensions of structure (see Table 1).

These dimensions also form a partial definition of our understanding of the structure concept - that is to say, if some theoretical concept is examined that can be placed on all or most of these scales, it is likely that we are discussing something related to structure, even if the theoretical concept has another name (such as network in actornetwork theory [Monteiro 2000] or formative context [Ciborra and Lanzara 1994]).

In the following sections, we examine three examples of adaptive theory focusing on different aspects of structure in IS. In each case, we examine both the theory and (briefly) the theoretical context or perspective. The purpose of the discussion is to identify theoretical understandings relating to the dimensions of structure outlined above. The theory analysis compares the three perspectives in relation to the structure dimensions.

\subsection{Adaptive Theory Example 1: Structurational Theories of IS (Social Theory Perspective)}

One way of framing the relationship between technical and social, or more precisely the relationship between a computer-based artifact and its social context, is to discuss the place of computer artifacts in social structure. This discussion is exemplified by recent contributions to the IS literature which have sought to adapt structuration theory (Giddens 1979, 1984; Giddens and Turner 1987) to theorize the IS field. A particular form of virtual social structure (and its emergent relationship with human agency) is of course central to structuration theory; IS adaptations try to establish the role of computerized technologies within than relationship, since this is not a project that Giddens himself undertook. Giddens (1984) thought of structure as

rules and resources recursively implicated in social reproduction, thus institutionalized features of social systems have structural properties in the sense that relationships are stabilized across time and space....[Structure] exist[s] only as memory traces, the organic basis of human knowledgeability, and is instantiated in action. 
Table 1. Dimensions of Structure

\begin{tabular}{|l|l|}
\hline \multicolumn{1}{|c|}{ Dimensions of Structure } & \multicolumn{1}{|c|}{ Description } \\
\hline Formation & $\begin{array}{l}\text { How a structure comes into existence. Is it preexisting as a } \\
\text { law of nature, socially constructed - perhaps emergent } \\
\text { from social actions - or built as an artifact? }\end{array}$ \\
\hline Ordering & $\begin{array}{l}\text { How the underlying pattern, framework, foundation, or } \\
\text { logic of structure can be understood. }\end{array}$ \\
\hline Socation & $\begin{array}{l}\text { Whether structure is virtual (i.e., social) or material } \\
\text { (physical) or both. Can structure therefore be located in } \\
\text { technology, making it acceptable to talk of technology } \\
\text { structures (and consequently technology effects), or is it } \\
\text { outside technology? }\end{array}$ \\
\hline Influence & $\begin{array}{l}\text { How widespread a pattern or framework need be to be } \\
\text { thought of as structure. Should a social structure be } \\
\text { society-wide, for instance, or can it be local to small } \\
\text { groups of people or individual situations? }\end{array}$ \\
\hline Evolution & $\begin{array}{l}\text { How determinant a structure is in enabling or constraining } \\
\text { related events and human actions. Should it be thought of } \\
\text { as a rule system, which is determinant of external events } \\
\text { and actions, or as influential (but not determinant) at some } \\
\text { conscious level which people can understand and at least } \\
\text { partly resist, perhaps working at an unconscious level to } \\
\text { influence or control our actions? Does it constrain, or } \\
\text { enable, or both? }\end{array}$ \\
\hline $\begin{array}{l}\text { The extent to which structure is enduring or persistent or } \\
\text { stable over time, whether and how it can alter or be altered. }\end{array}$ \\
\hline
\end{tabular}

IS academics had some difficulty with the virtuality of Giddens' structure concept and in some structurational technology models social structure is seen to be inscribed (Akrich 1994) into an information system. Typically this happens during the process of construction, with the finished product later influencing the behavior of its users: "designers incorporate... structures into technology...once complete the technology presents an array of social structures" (DeSanctis and Poole 1994). Once inscribed in technology, structure is no longer virtual, but material, and thus displays different kinds of endurance and influence which are not really compatible with Giddens' duality of structure and agency.

Orlikowski's earlier contributions (e.g., the duality of technology model, Orlikowski 1992), adopted a much moderated and qualified version of structure-in-technology: technology is both constituted by human agency and helps constitute institutional practice. Thus "information technology facilitates and constrains human action through the provision of interpretive schemes, facilities and norms" (Orlikowski and Robey 1991). However, in her most recent contribution, Orlikowski (2000) moves back to Giddens' position and locates structure entirely outside technological artifacts. By separating the artifact from its use and focusing on technologies-in-practice (the recurrent interaction that users have with technologies) Orlikowski relocates structure in the 
minds of users. Orlikowski (2000) asserts that technology structures are not external or independent of human agency; they are not out there, embodied in technologies simply waiting to be appropriated. Rather they are virtual, emerging from peoples repeated and situated interaction with particular technologies. In order to develop the virtual technology structure position, she has to rather underplay or ignore the effect of the technology designer in constituting the artifact according to a certain set of social norms (structure).

While Orlikowski's later position is more consistent with Giddens' view of structure (as rules and resources existing only in memory traces) than other earlier structurational IS positions, it is not entirely typical of thinking in other IS literatures with a social theory background. For example, it is commonplace among actor-network theorists to stress both the way that the social is inscribed into technological objects (see below). A compromise position is adopted by the social shaping school (Bijker et al. 1987; MacKenzie and Wajcman 1985). Grint and Woolgar (1997) argue that

inasmuch as technology embodies social aspects it is not a stable and determinate object (albeit one with political preferences inscribed into it), but an unstable and indeterminate artifact whose precise significance is negotiated and interpreted but never settled.

According to this account, social structure can be located in technological artifacts, but cannot be programmatically inscribed and later read off; social actors retain interpretive flexibility and the role of technology in social structure is fluid and emergent.

\subsection{Adaptive Theory Example 2: Deep and Surface Structures (Linguistic Perspective)}

Drawing on Chomsky's distinction between deep and surface structures in language, Wand and Weber (1995) distinguish an external view of phenomena around a computer system from the internal view represented in the black box of the system itself. The internal view consists of three types of structure (see Table 2).

Reflecting the dominant positivism of the American literature base, the success or failure of an information system's design is related to its correspondence to an external organizational reality or real world system, which is not obviously apparent (surface), but sometimes hidden (deep): the "unwritten rules of organizational functioning... [which] act to guide behavior by determining and defining appropriate and inappropriate behavior" (Leifer et al. 1994). Leifer et al. note that "deep structure... consists of the values, beliefs and unwritten rules in an organization...failure to identify this is one of the reasons why information systems fail." In a modified, realist formulation, Wand and Weber argue that "if information systems are to fulfil the requirements established for them, they must correctly embed the meaning of someone or some group's perception of the real-world system." The claim is that deep structures are both more true and more enduring than surface structures (which are of course easier to capture in the form of requirements): "good deep structures (in the information system) provide inherent stability to information systems in the face of change" (Wand and Weber 1995). 
Table 2. Wand and Weber's (1995) Three Types of Structure

\begin{tabular}{|l|l|}
\hline \multicolumn{1}{|c|}{ Structure Type } & \multicolumn{1}{c|}{ Description } \\
\hline Surface structure & $\begin{array}{l}\text { The way the system represents itself in the form of interface, } \\
\text { inputs, and outputs to the user. }\end{array}$ \\
\hline Deep structure & $\begin{array}{l}\text { Reflecting the meaning or underlying rule set of the real-world } \\
\text { system the computer system is intended to model. }\end{array}$ \\
\hline Physical structure & The technological implementation of the computer system. \\
\hline
\end{tabular}

Truex and Baskerville (1998) investigate the fidelity of such characterizations of deep structure to Chomsky's original theory and find that "the deep structure concept is intentionally used in the IS literature in a fairly loose way...as metaphorical and inspirational." Whereas Chomsky refers to the structure of language and its universal underlying grammar, the IS contributions view language as the window to the social structures that govern (in their view) organizational life. These are expressed in terms which resemble the expression of social structure discussed above. It is assumed that "surface structures are observable [via the medium of language] and that deep structures may be uncovered through them" (Truex and Baskerville 1998).

Although the IS adaptation of deep structure is discussed here because it is both well-known and explicitly relevant to our theme, it should be recognized that the Chomskian version of structure in linguistics is neither typical of the mainstream of IS interest in linguistic and semiotic theories, or much followed up in more recent literature. Most theories of language like to treat structure as enduring underlying patterns, and as rule sets, which either relate to or govern speech acts. These structures both constitute and are constituted by daily speech acts, much in the manner that Giddens relates social behavior (action) to social structure. Chomsky, however, goes further than most in tying these structures to underlying physiological traits of human brains.

The idea that a social order could be inscribed into a computer system and later decoded has its roots in an analogy with the writing and reading of texts (see Grint and Woolgar 1997). Understanding software as text (Lutje 2000) makes it hard to disentangle computer systems from the web of social and linguistic structures that are involved in its production and use. Computers become another media (like film or television) deeply embedded in the transmission of culture. Lutje (2000) further suggests that software as text can be understood as a network or web of semiotic signs. Semiotic understandings of the world can be used in the design process (Andersen 2001; Andersen and Mathiassen 2002; Liu 2000; Stamper 1996; Stamper et al. 2000), or in the understanding of user interpretation and the cultural effects of software (Stamper 1988). Although the materiality of software is a little elusive, computer systems are normally thought of as technological artefacts, and material artefacts can also be understood as signs, both reflecting and projecting heavily mediated interpretations of their social surroundings. Dahlbom and Mathiassen (1995) argue that this relationship means that changing the linguistic and social structures (culture) of a situation also normally involves changing the material structures (such as computer systems).

Linguistic and semiotic theorizations of IS overlap considerably with those that come from social theory. Stamper's (1973) semiotic framework, for example, contains 
a layer referring to the social world (beliefs, expectations, functions, commitments, contracts, law, culture). Conversely Orlikowski adopts Giddens (1984) duality of structure model, which incorporates signification, interpretive schemes, and communication. Hill (1988) neatly captures this overlap by speaking of technology as a cultural text whereby "experience of reality is mediated according to the values, assumptions, and focused capabilities that are sedimented into technological systems."

In what Hill describes as the "tragedy of technology," humans experience the world as "the remorseless working of things" wherein technology appears to command culture, and thus the trajectory of society. The script can be altered; however, the power of technological enframing makes us unaware of this possibility. Here Hill points to the invisibility of our socio-linguistic structures - we normally speak and act without conscious reference to them. Moreover, there are limits to our ability to understand and interpret the structures that we enact, and further limits to our individual and collective ability to respond to them. Interpretive flexibility in the face of technology exists only in so much as technology can be understood and responded to. If technologies appear inflexible to us, then we can only act in their structural shadows, despite the social constructionists' insistence upon interpretive flexibility.

\subsection{Adaptive Theory Example 3: IS Infrastructure (Social Study of Technology Perspective)}

Ciborra (2000) offers a fairly wide-ranging discussion of information systems as infrastructure. Here the materiality of computer systems as structure simply cannot be ignored. Dahlbom (2000) suggests four essential features of infrastructure which reflect the dimensions of structure identified earlier: it is a societal foundation, a stable structure, a common resource, and a common standard. Ciborra and his colleagues use Star and Ruhleder's (1996) eight dimensions of information infrastructures: embeddedness, transparency, reach or scope, learned as part of membership, links with conventions of practice, embodiment of standards, built on an installed base, and visible upon breakdown.

These dimensions highlight the relationship between social practice and infrastructure, where even the apparently technical details are socially constructed. As Monteiro and Hanseth (1996) note, "standards are neither ready made nor neutral: they inscribe organizational behavior deeply within their 'technical' details." Infrastructure is normally no more present in our consciousness than the socio-linguistic structures discussed earlier. Infrastructure is also emergent: "one important characteristic of infrastructure is to be 'recursive': it feeds upon existing infrastructures and represents the platform for future infrastructures" (Ciborra 2000).

However, the Star and Ruhleder's infrastructure dimensions also point to a central feature of the information infrastructure discussion: the understanding of structure as social and material structures enmeshed. The need to theorize both material and social elements explains the adoption of actor-network theory by information infrastructure theorists (Hanseth 2000; Hanseth and Braa 2000; Holmström and Stalder 2001; Monteiro 1998; Monteiro and Hanseth 1996). Part of the project of actor-network theorists is to overcome "the divide between material infrastructure and social super- 
structure" (Latour 1991). Thus ANT adopts the principle of symmetry, in which both the human and nonhuman can be analyzed according to the same principles (for a critique of this resolution, see Rose et al. (2003). In the information infrastructure literature, cables, computers, developers, users, and standards can all function as actors in the formation of a actor-network. ANT theorists assume the incorporation of sociolinguistic structures, so-called inscriptions, into technical objects (Akrich 1994). As argued by Callon (1991) and Monteiro and Hanseth (1996), inscriptions represent human interests embodied in socio-economic-technical networks that later define and distribute roles to human and nonhuman actors.

Although carefully distancing himself from the structure/agency cliché, which he disdainfully refers to as the pont aux ânes, Latour (1999) regretfully acknowledges the structural connotation of the modern, internet related, use of the word network. Although ANT is primarily concerned with the active formation of networks, many structural features of networks are also apparent, such as stability and influence (Callon 1991). Stressing the role of the material in stabilizing networks, Grint and Woolgar (1997) note that "there is a constant need to establish and re-produce the network. In part this can be achieved through material embodiment. Indeed networks based solely on human relations tend to be weak."

Irreversibility in networks, echoing Hill's (1988) argument, helps form the trajectory of society. Where the socio-linguistic structures of society are inscribed into the material technology text, technology becomes "society made durable" (Latour 1991) and retreat becomes difficult. Thus, for the information infrastructure theorists, the material and the social are inextricably entwined in the formation and evolution of new, enduring network/structures, their ordering, and influence.

\subsection{Theory Analysis}

In this section, each of the six dimensions of structure is examined through the perspective of the three adaptive theory examples. The objective is to outline the major areas of agreement and points of contention in the treatment of structure. The analysis is summarized in Table 3.

Formation: Structure is largely thought of as recursive; that is, emergent from previous structure and emerging from the present structure. Structuration theorists see it as entirely socially constructed, whereas infrastructure theorists see it as emergent from both social and technological structures, where the technological components are both socially shaped, but also influential in their own right. The language theorists are more concerned with preexisting rule sets, but only those influenced by Chomskian linguistics relate those to natural biological laws.

Ordering: This dimension reflected some diversity; the structurational view focuses on social structure and human agency in a technology context, the linguistic view on a relation between different levels of structure, and the infrastructural perspective on networks of human and nonhuman components. The perspectives are rather more complementary then contradictory, however, in as much as they could to some extent be combined.

Location: This dimension is the subject of contention. Orlikowski's (2000) structure-entirely-outside-technology position is a minority position. Wand and Weber 
Table 3. Dimensions of Structure Against Different Theoretical Perspectives

\begin{tabular}{|c|c|c|c|c|}
\hline $\begin{array}{l}\text { Dimensions } \\
\text { of Structure }\end{array}$ & Description & $\begin{array}{c}\text { Social } \\
\text { Structure } \\
\text { (Structuration } \\
\text { Theory) }\end{array}$ & $\begin{array}{c}\text { Linguistic/Semiotic } \\
\text { Structure } \\
\text { (Deep, Surface } \\
\text { Structure) }\end{array}$ & $\begin{array}{c}\text { Infrastructure } \\
\text { (Actor- } \\
\text { Network } \\
\text { Theory) }\end{array}$ \\
\hline Formation & $\begin{array}{l}\text { How a } \\
\text { structure } \\
\text { comes into } \\
\text { existence. }\end{array}$ & $\begin{array}{l}\text { Emergent } \\
\text { through action. }\end{array}$ & $\begin{array}{l}\text { Deep structure as law } \\
\text { of nature (Chomsky); } \\
\text { otherwise emergent } \\
\text { through communi- } \\
\text { cation. }\end{array}$ & $\begin{array}{l}\text { Socio- } \\
\text { technically } \\
\text { emergent. }\end{array}$ \\
\hline Ordering & $\begin{array}{l}\text { How the } \\
\text { foundation of } \\
\text { structure can } \\
\text { be under- } \\
\text { stood. }\end{array}$ & $\begin{array}{l}\text { Structure in } \\
\text { human memory } \\
\text { traces, } \\
\text { technology use. }\end{array}$ & $\begin{array}{l}\text { Structure inscribed in } \\
\text { technology. }\end{array}$ & $\begin{array}{l}\text { Structure in } \\
\text { technology and } \\
\text { social practice. }\end{array}$ \\
\hline Location & $\begin{array}{l}\text { Whether } \\
\text { structure is } \\
\text { virtual (i.e., } \\
\text { social) or } \\
\text { material } \\
\text { (physical) or } \\
\text { both. }\end{array}$ & $\begin{array}{l}\text { Structure } \\
\text { enables and } \\
\text { constrains } \\
\text { action, humans } \\
\text { retain } \\
\text { interpretive } \\
\text { flexibility. }\end{array}$ & $\begin{array}{l}\text { Structure influential } \\
\text { over communication } \\
\text { (linked culture and } \\
\text { technology text create } \\
\text { illusion of determined } \\
\text { society trajectory } \\
\text { [Hill]). }\end{array}$ & $\begin{array}{l}\text { Infrastructure } \\
\text { enables or } \\
\text { disables upon } \\
\text { breakdown. }\end{array}$ \\
\hline Scope & $\begin{array}{l}\text { How } \\
\text { widespread a } \\
\text { pattern or } \\
\text { framework } \\
\text { need be, to } \\
\text { be thought of } \\
\text { as structure. }\end{array}$ & $\begin{array}{l}\text { Micro and } \\
\text { macro. }\end{array}$ & Micro and macro. & $\begin{array}{l}\text { Organizational } \\
\text { and societal. }\end{array}$ \\
\hline Influence & $\begin{array}{l}\text { How deter- } \\
\text { minant a } \\
\text { structure is in } \\
\text { enabling or } \\
\text { constraining } \\
\text { related events } \\
\text { and human } \\
\text { actions. }\end{array}$ & $\begin{array}{l}\text { Social structure } \\
\text { in relation to } \\
\text { human agency. }\end{array}$ & $\begin{array}{l}\text { Mirroring of social } \\
\text { structure in techno- } \\
\text { logy (Wand and } \\
\text { Weber); linguistic } \\
\text { structure in relation to } \\
\text { communicative acts. }\end{array}$ & $\begin{array}{l}\text { Socio-technical } \\
\text { systems or } \\
\text { networks. }\end{array}$ \\
\hline Evolution & $\begin{array}{l}\text { The extent to } \\
\text { which } \\
\text { structure is } \\
\text { enduring } \\
\text { over time. }\end{array}$ & $\begin{array}{l}\text { Humans effect } \\
\text { changes in a } \\
\text { social context. }\end{array}$ & $\begin{array}{l}\text { Both material and } \\
\text { social structure } \\
\text { implicated in change. }\end{array}$ & $\begin{array}{l}\text { Emergent } \\
\text { socio-technical } \\
\text { change with } \\
\text { technology as } \\
\text { actor. }\end{array}$ \\
\hline
\end{tabular}

(1995) understand structure as internal to a computer system, the semiotics-based theorists assume that material (technological) structure mirrors and reinforces sociolinguistic structure, and the infrastructure theorists assume a socio-technical location for structure. However, in each case, structure is only partly visible. 
Scope: This dimension was less contentious. Although some contributions were more targeted at an organizational scope and some at a society level, there was a fairly general assumption that structure could operate at a micro and a macro level simultaneously. The infrastructuralists were the exception: here structure had to be a least organization-wide.

Influence: Influence is another slightly contentious dimension. The Chomskian theorists were the only ones to speak of determination: deep structures as rule systems determining organizational behavior. Otherwise structures were thought of as influential, but the degree of influence was disputed. The orthodox social constructivist position insists on humans' interpretive flexibility in the face of technology, whereas Hill's technology-as-text position suggests a much more powerfully influential role for technology. This notion of structure as beyond everyday human understanding and beyond humans' capacity to resist is also partly captured in the adaptation of the deep structure concept. The infrastructuralists had a slightly different position: structure as enabler (and consequent disabler upon breakdown).

Evolution: All perspectives regarded structures as relatively enduring. There is disagreement, however, on how structures can be changed, with highly knowledgeable humans as the driving force in the structurational accounts, but technologies and nonhuman actants more significant in other accounts.

In sum, we conclude from this analysis that the most contentious point about structure in the IS literature is its location. Briefly put, are the computer systems a part of our conception of structure or are they not? Accordingly, our integrative theory model concentrates on the relation of material structure to virtual structures (see section 4).

\section{RESEARCH METHODOLOGY}

\subsection{Research Approach}

The research presented in this paper can be classified as interpretive IS research (Walsham 1995a) in three ways.

First, following Markus and Robey's (1988) distinction between variance and process theories in IS research, the integrative model proposed can be regarded as a process theory meaning that "outcomes are not conceived as variables that can take on a range of values, but rather as discrete or discontinuous phenomena." Rather than providing a framework that explains structure in IS (e.g., consisting of a set of elements or variables with causal linkages), our intent is to understand the deeper structure of a phenomenon, which is believed can then be used to inform other settings" (Orlikowski and Baroudi 1991). We view the proposed integrative model as an attempt to provide an understanding of structure useful for both academics and practitioners to improve IS practice.

Second, our literature review is concentrated on more or less interpretive approaches to structure. Organizational scientists have long discussed the relationship between structure and technology. Various schools of organization theory such as Taylorism, the socio-technical school, and contingency theory (Galbraith 1973; Lawrence and Lorsch 1967) have explored this issue in order to understand how these elements interact with other organizational elements such as goals, participants, and environment (cf. Leavitt 1965). Recently, however, the IS field has adopted approaches 
to structure (and technology) that focus more on social structure and information technology, rather than on formal structure and production technologies. Recent adaptations of structuration theory (DeSanctis and Poole 1994; Orlikowski 1992, 2000; Orlikowski and Robey 1991), linguistic theory (Truex and Baskerville 1998), and actornetwork theory (Hanseth and Monteiro 1997; Monteiro 2000) are all examples of such approaches. We acknowledge this development in the field of IS by focusing on approaches to IS and structure that reflect this trend.

Third, the case used for developing and illustrating the theoretical model was conducted as part of an action research project on design and use of competence systems. The study draws on qualitative data collected through data sources such as focus groups, interviews, and observations.

\subsection{Research Design}

The research design is presented in Figure 1. We selected three approaches to structure in IS that all have been developed as theoretical adaptations of the reference disciplines in which they are grounded. The structurational, language, and infrastructural approaches display both agreements and disagreements over dimensions of structure such as formation, ordering, location, scope, influence, and evolution. On the basis of these agreements and disagreements, we present the integrative model of structure as a way of reconciling some difficulties with the theorization of structure found in current IS literature. The empirical data was also used to help develop the model, but in the paper serves to illustrate the explicative relevance of the integrative model in the context of competence systems design and use at Volvo IT.

\subsection{Data Collection and Analysis}

The case study at Volvo IT (for a description of the research site, see subsection 5.1) was conducted between November 1999 and December 2001. The study used multiple data sources including document reviews, focus group sessions, interventions, interviews, participant observation, testing of systems, and workshops.

Semi-structured interviews covering topics such as competence development, competence management, and work practice were conducted with 26 respondents in different job positions (account managers, business area managers, CEO, competence development managers, HR personnel, management consultants, project managers, sales managers, and programmers). The interviews lasted approximately 45 minutes and were later transcribed to facilitate the data analysis.

The data analysis was conducted applying the principles ofinterpretive field studies (Klein and Myers 1999). Consistent with these principles, we analyzed the data in an open-minded manner in order not to downplay potential new perspectives and ideas emerging in the iterative process of going back and forth between the theoretical conceptions that guided the research design and the story which the data tell (Klein and Myers 1999; Walsham 1995b). Concurring with the open coding technique originating in grounded theory (Strauss and Corbin 1997), the empirical data was analyzed in an iterative way, where initial categories generated were revised and refined until they adequately explained the data material. 


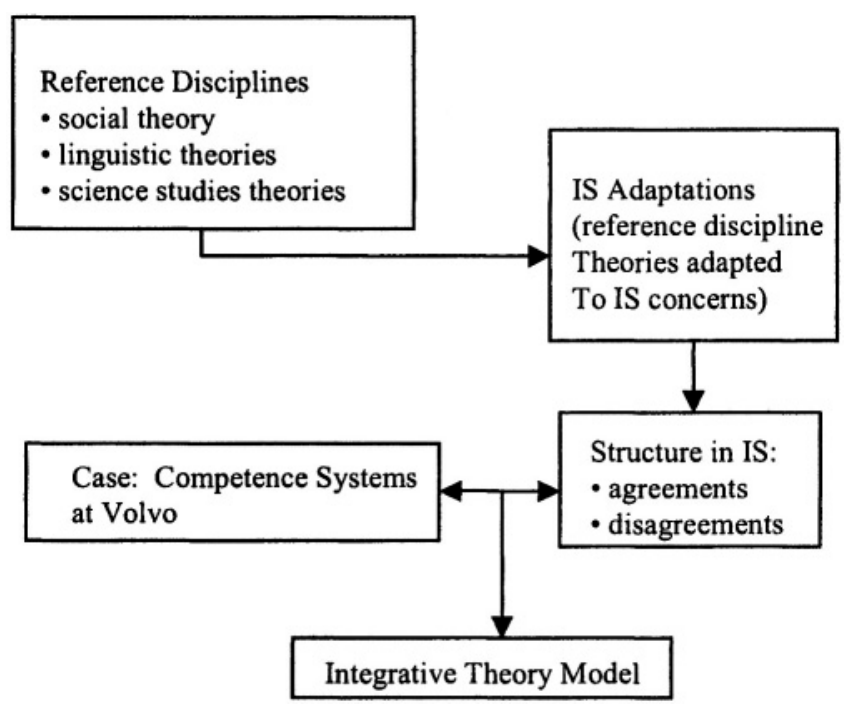

Figure 1. Research Design

\section{INTEGRATIVE THEORY MODEL: DEEP, SURFACE, MATERIAL STRUCTURES}

The integrative theory model (Figure 2) reflects some relative consensus about structure (see section 2.5 on theory analysis). It is recursive (formation); that is structure is seen as the preexisting frame for both speech acts and practical acts, which then reproduce and transform their formative structures. In this sense, it evolves out of itself. Structures represent shared patterns (ordering) of thought and belief which also become represented in material patterns (there are many makes and designs of computer, but they share many common characteristics). Structures operate at a local level (scope) to influence how we speak and act, but the cumulation of such influences results in societywide structure. Structures influence, rather than determine, our actions, but we do not necessarily have full understanding of them, so they can influence our behavior in ways about which we are not conscious. Where we are conscious of them we do not necessarily always have the ability to avoid their influence. Structures endure (evolution) but not necessarily unchanged - they can evolve slowly or fast. A more contentious issue is location (is a computer system itself a material structure?), and this is explicitly addressed by the model. Here we distinguish between socio-linguistic structures and material structures, where the type of material structure we are primarily interested in is computer systems, a computing infrastructure, or a computing technology.

Socio-linguistic structures represent the virtual patterns of thought and behavior of groups, organizations, and societies, which are also represented in the discourse and patterns of actions of their members. Socio-linguistic structures may be thought of as schemes of signification, legitimation, and domination, as values, norms, cultural associations, and shared cultural histories and meanings which both provide the formative context within which all communicative and non-communicative actions are 


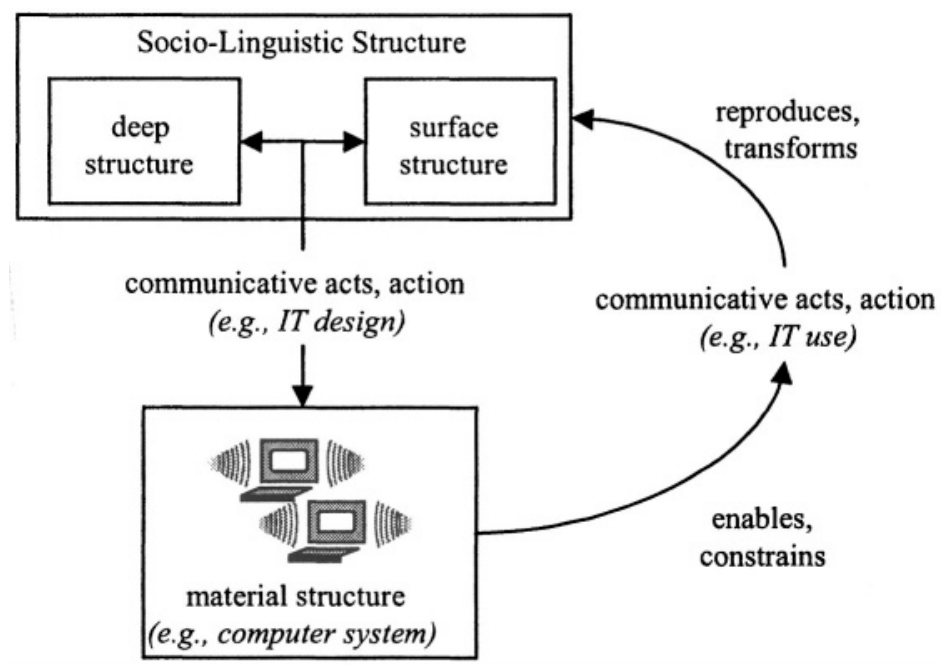

Figure 2. Deep, Surface, Material Structures

taken and, at the same time, the reference system against which they are interpreted and evaluated. In any social situation, discourse, or domain, some socio-linguistic structures are more in focus and more articulated than others. The structures which are ready at hand, easily comprehensible, and accessible we refer to as surface structures. For example, much of the business information systems literature focuses on task structure. However, many other structures may also be important features of the situation, although less apparent. They may be out of focus (i.e., simply not much thought or talked about in the situation), difficult to articulate (perhaps for political reasons), hard to recognize (such as widely held cultural prejudices), or unconscious. These are the deep structures of the situation. To some extent, the deeper structures can be revealed by discussion and analysis, but they are never fully knowable. There may be much interplay between deep and surface structures, but they should not be thought of as a rule system in which they determine each other, or determine communicative acts and actions.

Socio-linguistic structure is the context for human actions of all kinds. We distinguish two kinds of actions: those which are primarily speech-based (or communicative), and those which are primarily behavioral or task oriented-many actions are both. Structure can be less or more influential, but is never absent. One particular form of human action is the design, manufacture, and installation of material objects, including technological artefacts and computer systems. Some surface structures are normally consciously inscribed into material objects, but they may also carry the unconscious imprint of deep structures. Material structure (e.g., computing infrastructure) thus normally reflects socio-linguistic structure. Where the material objects are shared across groups or more widely, they can also be structural in the sense that they influence communicative and practical acts.

Material structure influences human action to a greater or to a lesser degree. Social structure is the reference system against which material structure is interpreted; however, material structure has physical characteristics that somewhat delimit interpretation. If 
the computer system locks the building at four o'clock, you cannot simply walk through the locked door. Socio-linguistic structures always refer to existing material structures (put another way, our current situation always contains both socio-linguistic and material structures). Therefore, socio-linguistic structures and material structures together make the context in which action is taken.

Material structures, together with their interpretations in the light of social structures, influence the actions of their users. A technology or computer system user has some, but not absolute, freedom to interpret the inscriptions that the designers consciously or unconsciously wrote into the technology object. Human actors have interpretive flexibility, the ability to interpret and respond to material structures in different ways, but this flexibility is heavily bounded by our cognitive limits. In using the technology objects, the users take actions, which often serve to reproduce the social structures inscribed into the objects, but may also change (transform) them.

In the following section, the theoretical model is used to analyze and explain competence management systems development at Volvo IT.

\section{COMPETENCE MANAGEMENT SYSTEMS DEVELOPMENT AT VOLVO IT}

\subsection{Competence Management at Volvo IT}

Volvo IT is the Volvo Group's resource and expertise center for IT systems. At the time of the research project (April-June, 2000), Volvo IT had approximately 2,500 employees. Approximately 1,400 of those worked in Sweden and roughly 900 in the Göteborg area where the head office is located. Analogous to many large organizations, the problem of knowing who within the organization knows what has become part of Volvo IT's surface structure or discourse. In 1999, when Volvo IT was formed, this problem became particularly evident. Consolidating the old Volvo data with the systems developers and other IT personnel from the product companies, Volvo IT expanded from 900 to 2,400 employees. The prevalent approach of using, for example, Excel spreadsheets as instruments (material structure) for project configuration and competence management became unmanageable. Volvo IT had only a vague overall picture (i.e., an undeveloped surface structure) of existing competence within the organization and could not conduct goal-directed competence management on neither the organizational nor the individual level. Resulting from this, Volvo IT decided to strengthen their competence management process by initiating a number of activities and projects.

An important initial activity was the attempt to establish a common understanding/ shared discourse of the notion of competence in the organization. In this work, the project management group used a published corporate report where competence was defined in terms of five aspects: skills, knowledge, experiences, relationships, and values. In addition to these aspects, motivation was identified as an inner source of energy required for activating competence ( $\mathrm{AB}$ Volvo 1987). While most project members seemed to appreciate such an understanding of competence, some actors clearly hesitated. In other words, it was unclear how far the surface structure or discourse was accepted, indicating a potential conflict with deep structures. The typical 
argument of those who questioned this competence view was that qualitative aspects like relationships, values, and motivation are mere complicating factors in that they are too difficult to codify and make explicit. The competence perspective suggested by the project management group (attempt to establish a surface structure) was obviously at odds with some wider understanding (deep structures) and the task of establishing a common appreciation or shared discourse/surface structure of competence in the organization turned out to be more complex than anticipated. These contrasting perspectives on competence resonate well with the underlying rationales ofjob-based and skill-based approaches to competence management.

\subsection{Job-Based and Skilled-Based Approaches to Competence Management}

Drawing on an underlying conception or deep structure of work as individuals matched to job roles (Fombrum et al. 1984; Ghorpade and Atchinson 1980), most existing approaches to competence management build on job descriptions (Lawler and Ledford 1992). Viewing jobs as relatively fixed positions requiring specific skills, the job-based approach is focused on filling jobs with individuals with the requisite skills to perform them. In this discourse, competence is a set of properties required for a specific job (Spencer and Spencer 1993). The focus is not skill per se, but rather what type of skills are needed to perform a certain work task (McClelland, 1973). Based on formalized explicit descriptions covering work tasks and required competence, employees' competencies are made visible and measurable. This perspective (underlying way of thinking or deeper structure) of competence management is associated with conventional managerial ideas of organization and working such as command and control, division of thinking and doing, hierarchical structures, machine bureaucracies, planning, and rational analysis.

Contrary to the job-based approach to competence management, the skilled-based approach is concentrated on the individual (Lawler and Ledford 1992). This approach/ discourse argues that competence management activities need to be aligned with the development of individuals so that the organization ends up with the right competence profile for each individual employee. Organizations should develop person descriptions that describe what competencies an individual has to develop to be effective in a specific work area. In order to support individual employees' ambitions to develop new competencies and take on new responsibilities, there is no permanent assignment of work activities. Instead, self-managing work teams are assigned responsibility for the performance of a particular work process (Lawler and Ledford 1992). This way of thinking about competence management can be described as an interest- and development-based view, where highly skilled and motivated independent workers take control of their own competence development, forming communities of interests, actively developing their own knowledge and skills, and directing the development of their careers. In this context, the deeper or underlying structure of management is about coordination and facilitation, decentralization of power, and democracy. 


\subsection{Project 1}

In an attempt to take a firmer grip on its competence management, Volvo IT initiated a pilot installation of Tieto Persona/Human Resource (TP/HR) in late 1999. Designed to support mapping, categorization, and visualization of an organization's competencies, TP/HR was based upon a preestablished competence classification where competencies were defined as functional skills (practical work tasks) and technical skills (methods or techniques used to perform the tasks). At the outset of the project, managers of the pilot group clearly articulated that TP/HR should be adapted and configured to handle both qualitative and quantitative aspects of competence: skills, knowledge, experiences, relationships, values, and motivation (an apparently agreed surface structure was thus developed). This could be described as an inclusive understanding of competence, reflecting both job-based and skill-based approaches. Although relationships, values, and motivation obviously are difficult to codify and make explicit, these qualitative aspects of competence were considered obvious parameters to include in the system. As the pilot project advanced this changed, however, and it was decided that these parameters were not to be covered by TP/HR's formalized competence classification (meaning that this apparently common surface structure was in trouble). Instead, the employees themselves were supposed to handle information about relationships, values, and motivation. In line with the rationale of the job-based approach to competence management, the pilot group thus concentrated exclusively on skills, knowledge, and experiences. Despite agreed communicative actions, people actually acted differently.

Volvo IT's idea was to use the representations of competencies as provided by TP/HR to match tasks with qualified people or to get an expert's view of a particular problem. It was assumed that the required competence resides somewhere in the organization and the TP/HR system's role was to support the identification of that particular competence in a rationalistic and effective way. This logic builds on the assumption that tasks are recurrent and competencies are largely stable over time and therefore reusable. The TP/HR system was primarily a management tool, including features for measuring the status of employees' competencies and gap analyses (here material structure reflected a deeper structure related to management command and control thinking). It was assumed that employees would regularly feed the system with competence information, although they did not get much in return. On the basis of managerial structure, it was assumed (wrongly) that employees do what they are instructed. This producer/ consumer dilemma undermined employees' motivation to use the TP/HR system.

Since relationships, values, and motivation were not included in the TP/HR's formalized competence classification, some employees used the free text area function to indicate personal experiences, competencies outside one's direct line of work, hobbies, or remarks about future plans (i.e., contrasting the designers' intentions as inscribed into TP/HR, users used their interpretive flexibility to use the system to reflect a different structure of competence). Although this area was indexed and thus searchable, the information could not be aggregated and it was not in any way related to the formal competence structure of the system. While pilot group managers initially communicated the need for a competence management system conveying a multifaceted 
appreciation of competence, the result of the TP/HR project was in fact a system substantiating and reinforcing traditional job-based principles of competence management.

The experience from the TP/HR project offered an opportunity for our research team to introduce and evaluate a technology, which, by being based on interest-driven actions instead of formalized representations, contrasted the basic tenet of TP/HR. More specifically, the first project inspired us to develop a competence management system (material structure) that inscribes a different surface structure (and maybe unconsciously the deeper individual choice structure) and investigate how such a system would influence wider organizational structures and practices.

\subsection{Project 2}

Building on the experience from the TP/HR project, our research team initiated a second project on the design and use of competence management systems. In line with the rationale of action research, the intention of this project was partly to make the organizational members aware of and appreciative of a broader understanding of competence (i.e., change the organizational surface structure in respect to competence), including the skill-based approach, partly to inform the design of competence management systems capable of embracing this new conception (i.e., inscribe structure into a computer system).

Designed and implemented as a recommender system (RS), the Volvo Information Portal (VIP) prototype was intended to provide the employees with targeted and relevant intranet information. In addition to the standard RS function, we added a find competence feature. This feature enabled the VIP users to enter a natural-language text describing a specific interest, e.g., database administration on an Oracle system. VIP would then list all users with matching agents, i.e., all users who had agents actively searching for information related to the specified interest. Obviously, the VIP prototype did not locate people with formalized competence but people with an interest in the subject area. To label this feature find competence was a deliberate provocation intended to cause the organizational members to reflect upon the relation between interest and competence. Reflecting a far more skill-based approach to the understanding of competence, VIP was designed to reinforce that understanding among the people who used it.

VIP was released on Volvo's intranet in January 2000 and 50 or so individuals were notified of its existence. No formal training was offered but an introduction e-mail was submitted to all interested parties and the prototype had built-in help files. Although the prototype was not explicitly announced or promoted to the larger audience, it was generally available to all Volvo employees. When we conducted our research, during the period April to June 2000, approximately 20 users had active agents. On the basis of how organizational members used this prototype to find information in which they were interested, our research team was able to inquire into how personal interest, embodied in information seeking activities, could be a means for identifying competence.

On the basis of our involvement in Volvo IT's competence management activities and experiences from TP/HR and VIP, we could derive three qualitatively different 
perceptions of competence: (1) competence as formalized description, (2) interest as competence, and (3) interest beyond competence. Although all three perceptions could be found in dialogues with Volvo IT employees, the first category clearly represents the dominating unreflected perspective, or deep structure. The introduction of the VIP system, however, made people question their assumptions and brought about a debate. To our surprise, we found many users ready to testify to the importance of an interestand action-driven (skill-based) competence view. A tangible outcome of our research is that Volvo IT has applied some of the results produced. Currently, Volvo IT is conducting a project aimed at improving the organization's competence management worldwide. Based on lessons learned from TP/HR and the VIP system, Volvo IT has decided that personal interest profiles should be included in the organization's competence descriptions. As a result of the research, there has been an organizationwide change, even among managers, in the surface structure related to competence. What was before passive and un-reflected (deep structure) is in the present situation more surface.

\section{CONCLUSION}

In this experiment in integrative theory building, we studied three related understandings of structure, as expressed in the IS literature. All of the perspectives are heavily dependent on theories from other disciplines. There is much overlap in the understanding of structure between the adaptations of linguistic and social theories. In both cases, structure is viewed as important bedrock and context in the development and use of computer systems. However, the linguists start with structure as the regularities and rule sets of language and its use (which is then expanded to encompass human behavior), whereas the social theorist start with the study of social practice (which cannot be understood without including the study of meaning expressed in language). The comparison with the infrastructure debate, however, exposes the main point of contention, which is, not surprisingly, the computer systems themselves. Should these be considered structural or not? If so, how can the processes by which they become structural and their later influence be explained?

We chose to follow the convention of thinking of a computer system as a material artifact (though there is much that is not particularly material about software) and explain the relation of structure and actions in terms of deep structure, surface structure, and material structure. In doing this, we adopt Chomsky's terminology, as Wand and Weber did, but without adopting his specific theoretical stance. We simply observe that a great deal of the effort IS researchers expend in adopting and adapting European theories of social behavior and meaning is devoted to trying to understand patterns of meaning and behavior in IS development and use that go beyond functional work-based actions of users and simple denotational uses of language. Both surface and deep structures can be seen as influential in the design and use of competencies management systems at Volvo IT. Underlying structural perceptions of competence (as job- or skillbased), in relation to other structural understandings of how a company should be managed relate to the choice and development of computer systems intended to assist with those activities. The computer systems themselves used in practice serve to help 
reproduce or to change the underlying structures. Understanding how the deep and surface structures of social practice and discourse are consciously and unconsciously embedded in material computer systems, by the actions of designers, and subsequently interpreted by other stakeholders and reincorporated in the production and reproduction of linguistic and social structures continues to be one of the most challenging areas of inquiry in the discipline.

We developed, in this paper, an example of integrative theory building. This form of theory building is contrasted with the more usual adaptive theory building, which borrows a theory from another discipline and adapts it to IS phenomena. Integrative theory building sets out to synthesize existing IS theories by examining their similarities and resolving their differences. Both forms of theory building can be combined with the collection and analysis of empirical data, but are not primarily reliant on it. Integrative theory building can be seen to have some advantages in comparison to the other forms of theory building. In relation to building theory based on empirics, it draws strength from serious consideration of the historical traditions of thought represented in theory. In relation to adaptive theory building, it is well-focused on IS concerns, because the theories integrated have already been adapted to the IS domain. It can also be seen as a cumulative form of IS theory making, in that it builds on earlier contributions (the American positivist tradition also seeks to be cumulative in adding to scientific knowledge). A potential disadvantage is that it is never likely to include the latest developments in related disciplines, which may be highly relevant. However, in relation to the development of the field, it has the advantage of trying to assimilate the understandings of previous researchers instead of minimizing them in the search for something more relevant or trendy - the next killer theory.

Nevertheless, there seem to be some natural limits to what can be achieved with integrative theory building. Theories to be integrated must be chosen with care for their relative similarities. The occasional positivist theory in this study jarred rather with the generally socially constructionist tone. It seems to be necessary to include some background to individual contributions to relate them both to their background discipline and to the wider use of that discipline within IS, but that makes the theory hard to understand and to present coherently-book form is possibly more appropriate than article form. It is further rather doubtful whether the resulting theory can be accepted by other researchers wedded to their background disciplines-integrative theory is always bound to be inconsistent or trivial in relation to any specific background discipline that it tries to incorporate. Despite these doubts, we suggest that integrative theory development (which bridges disciplines and builds on existing insights to define what is central to IS) is a viable way to build truly exportable IS theory, although it is likely to take some time and hard work.

\section{REFERENCES}

AB Volvo. "På rätt spår" [On the Right Track], Corporate Report, 1987.

Akrich, M. "The De-Scription of Technical Objects," in J. Law (Ed.), Shaping Technology/ Building Society: Studies in Sociotechnical Change, Cambridge MA: The MIT Press: 1994, pp. 205-224.

Andersen, P. B. "What Semiotics Can and Cannot Do for HCI," Knowledge-Based Systems (14:8), 2001, pp. 419-424. 
Andersen, P. B., and Mathiassen, L. "Semiotics in Information SystemsEngineering," Semiotica (142:1/4), 2002, pp. 381-395.

Baskerville, R. L., and Myers, M. D. "Information Systems as a Reference Discipline," MIS Quarterly (26:1), 2002, pp. 1-14.

Bijker, W. E., Hughes, T. P., and Pinch, T. (Eds.). The Social Construction of Technological Systems: New Directions in the Sociology and History of Technology, Cambridge, MA: MIT Press, 1987.

Callon, M. "Techno-Economic Networks and Irreversibility," in J. Law (Ed.), A Sociology of Monsters: Essays on Power, Technology and Domination, London: Routledge, 1991, pp. 132-161.

Ciborra, C. (Ed.). From Control to Drift, Oxford: Oxford University Press, 2000.

Ciborra, C. U., and Lanzara, G. F. "Formative Contexts and Information Technology: Understanding the Dynamics of Innovation in Organizations," Accounting, Management and Information Technologies (4:2), 1994, pp. 68-93.

Dahlbom, B. "Postface: From Infrastructure to Networking," in C. Ciborra (Ed.), From Control to Drift, Oxford: Oxford University Press, 2000, pp. 212-226.

Dahlbom, B., and Mathiassen, L. Computers in Context, Oxford: Blackwell, 1995.

DeSanctis, G., and Poole, M. S. "Capturing the Complexity in Advanced Technology Use: Adaptive Structuration Theory," Organization Science (5:2), 1994, pp. 121-147.

Fombrum, C., Tichy, N. M. et al. Strategic Human Resource Management, New York: John Wiley \& Sons, 1984.

Galbraith, J. Designing Complex Organizations, Reading, MA: Addison-Wesley, 1973.

Ghorpade, J., and Atchinson, T. J. "The Concept of Job Analysis: A Review and Some Suggestions," Public Personnel Management (9), 1980, pp. 134-144.

Giddens, A. Central Problems in Social Theory, London: Macmillan Press, 1979.

Giddens, A. The Constitution of Society, Cambridge, MA: Polity Press, 1984.

Giddens, A., and Turner, J. H. Social Theory Today, Cambridge, MA: Polity Press, 1987.

Grint, K., and Woolgar, S. The Machine at Work, Cambridge, MA: Polity Press, 1997,

Hanseth, O. "Actor-Network Theory and Information Infrastructures," in C. Ciborra (Ed.), From Control to Drift, Oxford: Oxford University Press, 2000.

Hanseth, O., and Braa, K. "Who's in Control: Designers, Managers or Technology," in C. Ciborra (Ed.), From Control to Drift, Oxford: Oxford University Press, 2000.

Hanseth, O., and Monteiro, E. "Inscribing Behavior in Information Infrastructure Standards," Accounting, Management \& Information Technology (7:4), 1997, pp. 183-211.

Hill, S. The Tragedy of Technology, London: Pluto Press, 1988.

Holmström, J., and Stalder, F. "Drifting Technologies and Multi-Purpose Networks: The Case of the Swedish Cashcard," Information and Organization (11), 2001, pp. 187-206.

Klein, H., and Myers, M. "A Set of Principles for Conducting and Evaluating Interpretive Field Studies in Information Systems," MIS Quarterly (23:1), 1999, pp. 67-93.

Latour, B. "Technology is Society Made Durable," in J. Law (Ed.), A Sociology of Monsters: Essays on Power, Technology and Domination, London: Routledge, 1991, pp. 103-131.

Latour, B. "On Recalling ANT," in J. Law and J. Hassard (Eds.), Actor Network Theory and After, Oxford: Blackwell Publishers, 1999, pp. 15-25.

Lawler, E. E., and Ledford, G. "A Skill-Based Approach to Human Resource Management," European Management Journal (10:4), 1992, pp. 383-391.

Lawrence, P. R., and Lorsch, J. W. Organization and Environment: Managing Differentiation and Integration, Boston: Harvard University Press, 1967.

Leavitt, H. J. "Applied Organizational Change in Industry: Structural, Technological and Humanistic Approaches," in J. March (Ed.), Handbook of Organizations, Chicago: Rand McNally, 1965, pp. 1144-70.

Lee, A. "Editor's Comments: MIS Quarterly's Editorial Policies and Practices," MIS Quarterly (25:1), 2001, pp. iii-vii. 
Leifer, R., Lee, S., and Durgee, J. "Deep Structures: Real Information Requirements Determination," Information \& Management (27:5), November 1994, pp. 1-27.

Liu, K. Semiotics in Information Systems Engineering, Cambridge, England: Cambridge University Press, 2000.

Lutje, I. Software som Tekst, Aalborg, Denmark: Aalborg Universitetsforlag, 2000.

MacKenzie, D., and Wajcman, J. (Eds.). The Social Shaping of Technology, Milton Keynes, England: Open University Press, 1985.

Markus, M. L., and Robey, D. "Information Technology and Organizational Change: Causal Structure in Theory and Research," Management Science (24:5), 1988, pp. 583-598.

McClelland, D. C. "Testing for Competence Rather than for 'Intelligence," American Psychologist (28), 1973, pp. 1-14.

Monteiro, E. "Actor-Network Theory and Information Infrastructure," in C. U. Ciborra (Ed.), From Control to Drift, Oxford: Oxford University Press, 2000, pp. 71-86.

Monteiro, E. "Scaling Information Infrastructure: The Case of Next-Generation IP in the Internet," Information Society (14:3), 1998, pp. 229-245.

Monteiro, E., and Hanseth, O. "Social Shaping of Information Infrastructure," in W. J. Orlikowski, G. Walsham, M. Jones, and J. I. DeGross (Eds.), Information Technology and Changes in Organizational Work, London: Chapman \& Hall, 1996.

Nambisan, S. "Information Systems as a Reference Discipline for New Product Development," MIS Quarterly (27:1), 2003, pp. 1-18.

Orlikowski, W. J. "The Duality of Technology: Rethinking the Concept of Technology in Organizations," Organization Science (3:3), 1992, pp. 398-429.

Orlikowski, J. "Using Technology and Constituting Structures: A Practice Lens for Studying Technology in Organizations," Organization Science (11:4), July-August 2000, pp. 404-428.

Orlikowski, W. J., and Baroudi, J. J. "Studying IT in Organizations: Research Approaches and Assumptions," Information Systems Research (2:1), 1991, pp. 1-28.

Orlikowski, W. J., and Robey, D. "IT and the Structuring of Organizations," Information Systems Research (2:2), 1991, pp. 143-169.

Rose, J., Jones, M., and Truex, D. "The Problem of Agency: How Humans Act, How Machines Act," in ALOIS Workshop: Action in Language. Organizations and Information Systems, Linköping University, Linköping, Sweden, 2003, pp. 91-106.

Spencer, L. M., and Spencer, S. M. Competence at Work: Models for Superior Performance, Chichester, England: John Wiley \& Sons, 1993.

Stamper, R. "Analyzing the Cultural-Impact of a System," International Journal of Information Management (8:2), 1988, pp. 107-122.

Stamper, R. Information in Business and Administrative Systems, New York: John Wiley and Sons, 1973.

Stamper, R. "Signs, Information, Norms and Systems," in B. Holmqvist, P. B. Andersen, H. Klein, and R. Posner (Eds.), Signs of Work, Berlin: Gruyte. 1996.

Stamper, R., Liu, K. C., Hafkamp, M., and Ades, Y. "Understanding the Roles of Signs and Norms in Organizations: A Semiotic Approach to Information Systems Design," Behavior \& Information Technology (19:1), 2000, pp. 15-27.

Star, S. L., and Ruhleder, K. "Steps Toward an Ecology of Infrastructure: Design and Access for Large Information Spaces," Information Systems Research (7:1), 1996, pp. 111 -34.

Strauss, A., and Corbin, J. Grounded Theory in Practice, London: Sage Publicatoins, 1997.

Truex, D., and Baskerville, R. "Deep Structure or Emergence Theory: Contrasting Theoretical Foundations for Information Systems Development," Information Systems Journal (8:2), 1998, pp. 99-118.

Walsham, G. "The Emergence of Interpretivism in IS Research," Information Systems Research (6:4), 1995a, pp. 376-394.

Walsham, G. "Interpretive Case Studies in IS Research: Nature and Method," European Journal of Information Systems (4), 1995b, pp. 74-81. 
Wand, Y., and Weber, R. "On the Deep Structure of Information Systems," Information Systems Journal (5:3), July 1995, pp. 203-223.

\section{ABOUT THE AUTHORS}

Ola Henfridsson is the manager of the Telematics Group at the Viktoria Institute, Göteborg, Sweden. Dr. Henfridsson is also an assistant professor in Informatics at the School ofInformation Science, Computer and Electrical Engineering, Halmstad University. He holds a Ph.D. degree in Informatics from Umeå University, Sweden, and is a member of the editorial board of the Scandinavian Journal of Information Systems. Dr. Henfridsson has published his research in journals such as Accounting, Management \& Information Technologies, Database, The Information Systems Journal, The Journal of Information \& Knowledge Management, and The Scandinavian Journal of Information Systems. Dr Henfridsson can be reached at ola.henfridsson@viktoria.se.

Rikard Lindgren is a member of the Telematics Group, Viktoria Institute, Göteborg, Sweden. Dr. Lindgren is also an assistant professor in Informatics at School of Economics and Commercial Law, Göteborg University, and at the School of Information Science, Computer and Electrical Engineering, Halmstad University. He holds a Ph.D. degree in Informatics from Göteborg University, Sweden. Dr. Lindgren has published his research in publication outlets such as The European Journal of Information Systems, The Journal of Information \& Knowledge Management, The Journal of Knowledge Management Practice, and The Scandinavian Journal of Information Systems. Dr. Lindgren can be reached at rikard,lindgren@ viktoria.se.

Jeremy Rose is an associate professor at the Department of Computing Science, Aalborg University, Denmark. He is currently a member of the PITNIT and SPV research projects in Denmark, and active as a member of the IFIP WG8.2 community. His research interests are principally concerned with IT and organizational change, the management of IT, and IS development. The research approach combines empirical insights with theoretical perspectives to produce practically useful knowledge around various contemporary technologies in different types of organizational settings. He has published in management, systems and IS forums. Further details and some publications are available at http://www.cs.auc.dk/ jeremy/. He can be reached at jeremy@cs.auc.dk. 